\title{
BMJ
}

\section{The effect of a multifaceted empowerment strategy on decision making about the number of embryos transferred in in vitro fertilisation: randomised controlled trial}

\author{
Arno van Peperstraten, resident in obstetrics and gynaecology, ${ }^{1}$ Willianne Nelen, senior research fellow, ${ }^{1}$ \\ Richard Grol, professor in quality of care, ${ }^{2}$ Gerhard Zielhuis, professor of epidemiology, ${ }^{3}$ Eddy Adang, senior \\ lecturer in health economics, ${ }^{3}$ Peep Stalmeier, senior research fellow, ${ }^{3,4}$ Rosella Hermens, senior research \\ fellow, ${ }^{2}$ Jan Kremer, professor in reproductive medicine ${ }^{1}$
}

${ }^{1}$ Department of Obstetrics and Gynaecology, Radboud University Nijmegen Medical Centre,

PO Box 9101, 6500 HB Nijmegen, Netherlands

${ }^{2}$ Scientific Institute for Quality of Healthcare, Radboud University Nijmegen Medical Centre

${ }^{3}$ Department of Epidemiology, Biostatistics and HTA, Radboud University Nijmegen Medical Centre

${ }^{4}$ Department of Radiation Oncology, Radboud University Nijmegen Medical Centre Correspondence to: A M van Peperstraten A.vanpeperstraten@obgyn.umcn.nl

Cite this as: BMJ 2010;340:C2501 doi:10.1136/bmi.c2501

\section{ABSTRACT}

Objective To evaluate the effects of a multifaceted empowerment strategy on the actual use of single embryo transfer after in vitro fertilisation.

Design Randomised controlled trial.

Setting Five in vitro fertilisation clinics in the Netherlands. Participants 308 couples (women aged 440 ) on the waiting list for a first in vitro fertilisation cycle. Interventions The multifaceted strategy aimed to empower couples in deciding how many embryos should be transferred. The strategy consisted of a decision aid, support of a nurse specialising in in vitro fertilisation, and the offer of reimbursement by way of an extra treatment cycle. The control group received standard care for in vitro fertilisation.

Main outcome measures Use of single embryo transfer in the first and second treatment cycles as well as decision making variables and costs of the empowerment strategy. Results After the first treatment cycle, single embryo transfer was used by $43 \%(65 / 152)$ of couples in the intervention group and $32 \%(50 / 156)$ in the control group (difference 11\%, 95\% confidence interval $0 \%$ to $22 \%$; $\mathrm{P}=0.05)$. After the second treatment cycle, single embryo transfer was used by $26 \%(14 / 154)$ of couples in the intervention group compared with $16 \%(8 / 51)$ in the control group (difference $10 \%,-6 \%$ to $26 \% ; P=0.20$ ). Compared with couples receiving standard care, those receiving the empowerment strategy had significantly higher empowerment and knowledge levels but no differences in anxiety levels. Mean total savings per couple in the intervention group were calculated to be $€ 169.75$ (£146.77; \$219.12).

Conclusions A multifaceted empowerment strategy encouraged use of single embryo transfer, increased patients' knowledge, reduced costs, and had no effect on levels of anxiety or depression. This strategy could therefore be an important tool to reduce the twin pregnancy rate after in vitro fertilisation. This trial did not, however, demonstrate the anticipated $25 \%$ difference in use of single embryo transfer of the power calculation. Trial registration ClinicalTrials.gov NCT00315029.

\section{INTRODUCTION}

Empowering patients is essential for good medical decision making and has been mentioned as an essential characteristic of good quality care. ${ }^{1-3}$ Patient empowerment implies a process of informing patients and providing them with the necessary tools and autonomy to adopt an active role in decision making. It is supposed to ensure that patients' experiences and opinions are integrated into clinical decisions, as well as to encourage doctors and researchers to focus on patient centred outcomes. ${ }^{4}$ However, the effect of patient empowerment, especially within complex decision making processes, is still being debated. Concerns were raised that patients might decline responsibility for decision making or that they would choose suboptimal or most expensive options. ${ }^{56}$

An example of a complex and important decision making problem is the number of embryos transferred after in vitro fertilisation. The transfer of only one embryo will prevent a multiple pregnancy with the associated complications for the mother and neonates. ${ }^{7-9}$ Single embryo transfer may also be disadvantageous, however, because double embryo transfer results in higher live birth rates per treatment cycle (odds ratio 2.1, 95\% confidence interval 1.7 to $2.7^{8}$ ). Therefore, compared with the transfer of multiple embryos, single embryo transfer could imply a necessity for more cycles to achieve pregnancy. ${ }^{10-12}$ This balance between the risk for complications of multiple births and optimal chance of pregnancy creates a complex decision making problem. Although professionals and policy makers have launched initiatives to encourage the use of single embryo transfer, ${ }^{13}$ it has not been successfully implemented in clinical practice. In 2004, the European multiple pregnancy rate after in vitro fertilisation was still $23 \%$, and single embryo transfer was used in only $19 \%$ of all cycles. ${ }^{14}$

Lack of knowledge about the pros and cons of single embryo transfer and the costs of the potentially necessary additional cycles are important barriers for use of single embryo transfer. ${ }^{15-17}$ On the basis of these 
Table 1|Characteristics of participating couples; intention to treat population. Values are numbers (percentages) unless stated otherwise

\begin{tabular}{|c|c|c|}
\hline Characteristics & $\begin{array}{l}\text { Intervention group } \\
\qquad(n=152)\end{array}$ & $\begin{array}{l}\text { Control group } \\
(n=156)\end{array}$ \\
\hline Previous successful IVF/ICSI treatment & 23/152 (15) & $25 / 156(16)$ \\
\hline Mean (SD) age of woman (years) & $32.0(3.9)$ & $31.7(4.2)$ \\
\hline Mean (SD) duration of infertility (years) & $2.2(1.8)$ & $2.3(2.0)$ \\
\hline Primary infertility & $99 / 152(65)$ & $102 / 156(65)$ \\
\hline IVF & $69 / 136(51)$ & $61 / 135(45)$ \\
\hline ICSI & $67 / 136(49)$ & $74 / 135(55)$ \\
\hline \multicolumn{3}{|l|}{ Diagnostic categories of infertility: } \\
\hline Male factor & $83 / 143(58)$ & $102 / 149(69)$ \\
\hline Unexplained & $36 / 143(25)$ & 20/149 (13) \\
\hline Endometriosis & $7 / 143(5)$ & $9 / 149(6)$ \\
\hline Tubal factor & $10 / 143(7)$ & $10 / 149(7)$ \\
\hline Other & $7 / 143(5)$ & $8 / 131(5)$ \\
\hline \multicolumn{3}{|l|}{ Educational level: } \\
\hline High school or less & $3 / 148(2)$ & 4/156 (3) \\
\hline Vocational education & $21 / 148(14)$ & $26 / 156(17)$ \\
\hline Pre-college or graduate education & $63 / 148(43)$ & $63 / 156(40)$ \\
\hline Completed college or graduate & $61 / 148(41)$ & $63 / 156(40)$ \\
\hline \multicolumn{3}{|l|}{ Monthly income $(€)$ : } \\
\hline 1100 to 1760 & 4/150 (3) & $2 / 155$ (1) \\
\hline 1760 to 2750 & $19 / 150(13)$ & 28/155 (18) \\
\hline$>2750$ & $106 / 150(71)$ & $106 / 155(68)$ \\
\hline Decided not to tell & $21 / 150$ (13) & 19/155 (13) \\
\hline
\end{tabular}

$€ 1.00$ (£0.85; \$1.23).

$\mathrm{IVF}=$ in vitro fertilisation; ICSI=intracytoplasmic sperm injection.

barriers, we developed a multifaceted strategy to empower couples for the decision about the number of embryos transferred. This strategy consisted of an evidence based decision aid, support of an in vitro fertilisation nurse, and reimbursement of an additional cycle for couples for whom the decision for single embryo transfer caused a reduced chance of pregnancy. We evaluated the effects of this multifaceted empowerment strategy on the actual number of embryos transferred, the impact on the decision making process, and costs related to the strategy.

\section{METHODS}

In the Netherlands, in vitro fertilisation (including intracytoplasmic sperm injection) is carried out in 13 licensed hospitals: eight university hospitals, four general hospitals, and one private clinic. In hospitals without a licence, professionals can start up and monitor in vitro fertilisation but refer to a licensed hospital for the retrieval of oocytes and embryo transfer. The current average pregnancy rate per in vitro fertilisation cycle in the Netherlands is about $24 \% .{ }^{18}$ Most couples who do not achieve pregnancy after a first cycle undergo successive cycles. The Dutch national healthcare system reimburses the costs of the first three cycles, but only if a maximum of two embryos are transferred. Before the start of this trial, it was standard practice in the participating centres that couples and their doctor shared the decision making process between single or double embryo transfer. Pros and cons of both options were discussed and similar neutral information was available for couples on the department's website. By then (2005) 39\% of the couples underwent single embryo transfer after the first cycle. ${ }^{19}$

\section{Design, participants, and sample size}

The randomised controlled trial was designed to test the hypothesis that a multifaceted empowerment strategy could encourage the use of single embryo transfer and reduce the number of twin pregnancies in a cost effective way. We compared the empowerment strategy in addition to standard practice for in vitro fertilisation with standard practice only.

Our randomised controlled trial was carried out in two licensed hospitals and three associated clinics and included couples on the waiting list for in vitro fertilisation between November 2006 and July 2007. Follow-up was continued until December 2008. The couples provided written informed consent before participation.

The criteria for inclusion were couples on the waiting list for a first in vitro fertilisation cycle ever or a first cycle after previous successful in vitro fertilisation, with the women younger than 40. A strict medical indication for preventing twin pregnancies (anomalies of the uterus, for example) made single embryo transfer mandatory, and was therefore an exclusion criterion.

Randomisation took place centrally using a computer generated randomisation list. Participants were randomised in blocks of four couples. A secretary outside our department was the only person with access to the randomisation list. She randomised the couples on the day consent was received and informed the couple that same day. Because of the nature of the intervention it was not possible to blind the participants or in vitro fertilisation doctors to the allocation. Participation in our trial did not change the normal in vitro fertilisation routine.

We determined that to detect a $25 \%$ difference in use of single embryo transfer between the groups compared with the baseline of $39 \%$, with an $\alpha$ of 0.05 , two sided testing, and a power of 0.80 , we needed at least 123 couples eligible for analysis. However, because participants were included and randomised before the treatment began, not all couples started with in vitro fertilisation (for instance, because of a spontaneous pregnancy or ending of the relationship). Taking these potential reasons for dropout into account, we aimed for about 300 couples for inclusion.

\section{Interventions}

The control group received standard in vitro fertilisation care, including a session in which the number of embryos transferred was discussed. In addition to this standard care, the intervention group received a multifaceted empowerment strategy. The elements of the strategy were sent by post, because use of the internet or email could have made elements of the intervention available to the control group. Couples in the intervention group were sent a decision aid, developed at our department, about the number of embryos transferred (available in English at www.umcn.nl/ivfda-en 


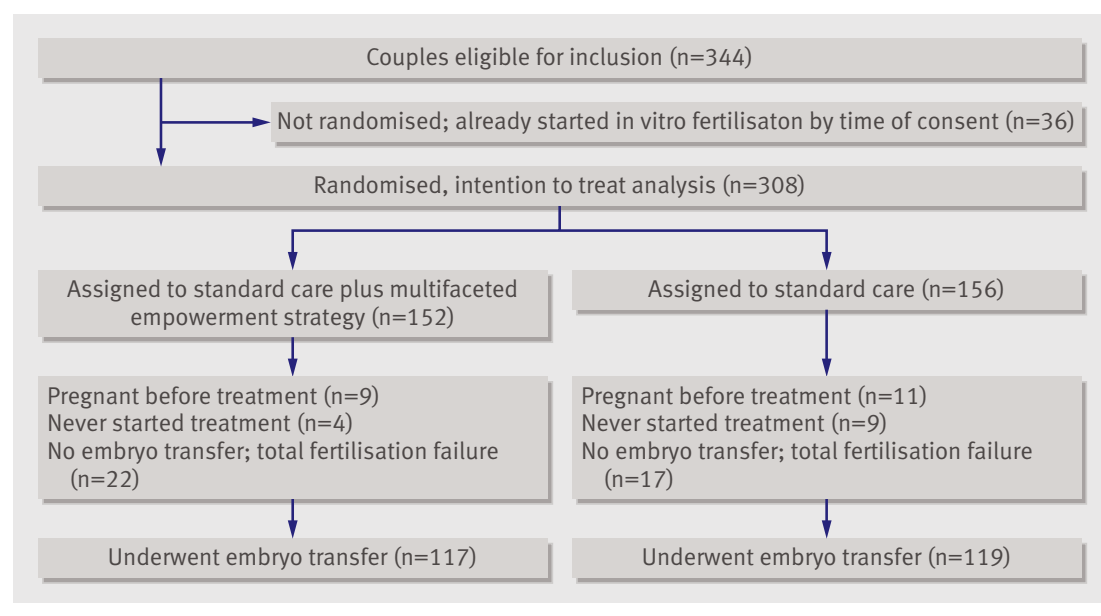

Trial profile general self efficacy scale to obtain levels of empowerment. ${ }^{22}$ Experienced knowledge levels were measured with self grading. Actual knowledge was measured using an 11 item multiple choice test. We monitored decision evaluation scores by means of a 15 item questionnaire, which included three domains; satisfaction/uncertainty, informed choice, and decision control. ${ }^{23}$ We determined anxiety and depression levels with the state trait anxiety inventory ${ }^{24}$ and the Beck depression inventory. ${ }^{25}$

We evaluated the costs associated with implementation of the empowerment strategy in clinical in vitro fertilisation practice. This was done from a healthcare perspective and determined the difference in total costs per couple between groups. We included all the costs for couples in the intervention group, including those couples who discontinued treatment. This exposure was registered on an exposure form (one for every specific couple), which was filled in each time the couple underwent parts of the intervention. We calculated costs on the basis of actual exposure to the different elements of the strategy. We excluded protocol driven costs for this specific trial, including those for the development of the decision aid. Costs included were those associated with all elements of the intervention (printing and distribution of the decision aid, the nurse, and the reimbursement offer), as well as the medical costs associated with additional cycles necessary to compensate for reduction in chance of pregnancy as a result of using single embryo transfer and the medical costs associated with the difference in frequency of singleton and twin pregnancies. For intervention costs we determined print and postal costs of the decision aid from actual expenses. Costs of the nurse were based on training hours and timing of the counselling sessions. Prices were determined from guidelines for cost related research in the Netherlands. ${ }^{26}$ For the surplus of couples in the intervention group who underwent embryo transfer and did not achieve a pregnancy compared with these couples in the control group, we calculated the costs for the additional cycles on the assumption that couples needed an average of 1.5 cycles compensation after a failed first cycle and one cycle compensation after a second failed cycle. The couples in the intervention group who had chosen single embryo transfer in the first and second cycle and who did not achieve a pregnancy after three cycles in total, qualified for reimbursement of a fourth cycle. These costs were included as well. From a previous analysis at our department we determined the costs per cycle and the medical costs (including antenatal care and hospital admission from pregnancy to six weeks after delivery) per singleton or twin pregnancy; a cycle costing $€ 2071$, a singleton pregnancy $€ 2788$, and a twin pregnancy $€ 14727 .{ }^{27} \mathrm{We}$ adjusted all unit costs to 2008 Euros by using the consumer price index as published by the Central Bureau of Statistics in the Netherlands (http://statline.cbs.nl/statweb).

\section{Statistical analysis}

All analyses were carried out in the intention to treat population. For both study groups we described the 
Table 2|Single embryo transfer use and pregnancy outcomes after first in vitro fertilisation cycle. Values are numbers (percentages) unless stated otherwise

\begin{tabular}{lcccc} 
First cycle & $\begin{array}{c}\text { Intervention } \\
\text { group }(\mathrm{n}=152)\end{array}$ & $\begin{array}{c}\text { Control group } \\
(\mathrm{n}=156)\end{array}$ & $\begin{array}{c}\text { \% difference } \\
(\mathbf{9 5 \%} \mathrm{Cl})\end{array}$ & P value \\
No choosing single embryo transfer & $65(43)$ & $50(32)$ & $11(0$ to 22$)$ & 0.05 \\
\hline Ongoing pregnancies* & $48(32)$ & $59(38)$ & $6(-4$ to 17$)$ & 0.25 \\
\hline Twin pregnancies & $6(4)$ & $10(6)$ & $2(-3$ to 7$)$ & 0.33 \\
\hline
\end{tabular}

Analyses in intention to treat population.

*>12 weeks' gestation. observed between the groups. Seven couples in the intervention group had spontaneous ongoing pregnancies before the start of in vitro fertilisation compared with nine couples in the control group. Moreover, four couples in the intervention group never started treatment compared with nine couples in the control group. The reasons for quitting were diverse. After oocyte retrieval and fertilisation, 236 couples had at least one embryo available and underwent embryo transfer. Thirty couples in the intervention group had only one embryo available for transfer compared with 23 couples in the control group. For 188 couples this treatment was the first ever in vitro fertilisation cycle. Forty eight couples had undergone successful in vitro fertilisation previously.

\section{Effectiveness}

Table 2 shows the actual use of single embryo transfer and the number of ongoing and twin pregnancies after the first cycle. In the intervention group 43\% (65/152) of couples chose single embryo transfer compared with $32 \%(50 / 156)$ in the control group (difference 11\%, $95 \%$ confidence interval $0 \%$ to $22 \% ; \mathrm{P}=0.05)$. Multivariable analysis showed that the odds ratio for this $11 \%$ difference did not change after addition of the potential confounders, such as the woman's age or the presence of a good quality embryo. The difference in use of single embryo transfer was more pronounced among the 48 couples who had previously undergone in vitro fertilisation than the group of 188 couples who were undergoing their first ever cycle: $64 \%(16 / 25) v$ $35 \%(8 / 23), \mathrm{P}=0.04$ compared with $53 \%$ (49/92) v 44\% (42/96). The control group had 11 more ongoing pregnancies than the intervention group $(\mathrm{P}=0.27)$ but also four more twin pregnancies $(\mathrm{P}=0.32)$. In total, $105 \mathrm{cou}-$ ples underwent a second cycle. In this second cycle, single embryo transfer was used in $26 \%(14 / 54)$ of the couples in the intervention group compared with $16 \%$ $(8 / 51)$ in the control group (difference $10 \%,-6 \%$ to $26 \% ; \mathrm{P}=0.20)$. After the second cycle the control group had two more ongoing pregnancies than the intervention group $(17 / 51 \quad(33 \%)$ v $15 / 54 \quad(28 \%)$; $\mathrm{P}=0.54)$ but two extra twin pregnancies as well $(6 / 51$ $(12 \%)$ v $4 / 54(7 \%) ; \mathrm{P}=0.45)$.

Table 3 lists the variables related to patient empowerment in both groups. The proportion of couples in the intervention group who wanted to decide for themselves on the number of embryos transferred (with the doctor as adviser only and not someone with influence on the decision) increased from $77 \%(116 / 150)$ to $91 \%$ (116/127), while this percentage remained $73 \%$ $(99 / 135)$ in the control group $(\mathrm{P}<0.001)$. Levels of both experienced knowledge $(\mathrm{P}=0.001)$ and actual knowledge $(\mathrm{P}<0.001)$ were higher in the intervention group $(n=123)$ compared with the control group $(n=132)$. The decision evaluation scale did not differ significantly in satisfaction-uncertainty or control levels, but couples in the intervention group $(n=124)$ reported a better informed choice compared with those in the control group $(\mathrm{n}=128 ; \mathrm{P}=0.01)$. This better informed choice persisted until five weeks after embryo transfer 
Table $3 \mid$ Decision making outcomes at baseline and after exposure to multifaceted intervention but before start of in vitro fertilisation (IVF)

\begin{tabular}{|c|c|c|c|c|c|c|}
\hline \multirow[b]{2}{*}{ Variables } & \multicolumn{3}{|c|}{ Baseline } & \multicolumn{3}{|c|}{ After multifaceted intervention (before IVF) } \\
\hline & Intervention group & Control group & $P$ value & Intervention group & Control group & $P$ value \\
\hline No of fully empowered couples & $116 / 150$ & $112 / 154$ & \multirow{2}{*}{0.35} & $116 / 127$ & $99 / 135$ & \multirow{2}{*}{$<0.001$} \\
\hline$\%(95 \% \mathrm{Cl})$ & 77 (70 to 83$)$ & $73(65$ to 79$)$ & & $91(85$ to 95$)$ * & $73(65$ to 80$)$ & \\
\hline \multicolumn{7}{|l|}{ Mean knowledge $(0-10) \dagger(95 \% \mathrm{Cl})$ : } \\
\hline Experienced & $5.7(5.4$ to 6.1$)$ & $5.8(5.4$ to 6.2$)$ & 0.72 & 7.7 (7.5 to 7.8$) \ddagger$ & $7.2(7.0$ to 7.4$)$ & 0.001 \\
\hline Actual & - & - & - & $6.2(5.7$ to 6.7$)$ & $4.3(4.0$ to 4.7$)$ & $<0.001$ \\
\hline \multicolumn{7}{|c|}{ Mean decision evaluation scale $(1-5)+(95 \% \mathrm{Cl})$ : } \\
\hline Satisfaction-uncertainty & - & - & - & 3.9 (3.8 to 4.0$)$ & $4.0(3.9$ to 4.1$)$ & 0.76 \\
\hline Informed choice & - & - & - & $4.1(4.0$ to 4.2$)$ & 3.8 (3.7 to 3.9 ) & 0.001 \\
\hline Control & - & - & - & $4.4(4.3$ to 4.5$)$ & $4.5(4.4$ to 4.5$)$ & 0.33 \\
\hline Anxiety level (20-80) & 35.6 (33.9 to 37.3$)$ & 34.6 (33.1 to 36.1$)$ & 0.40 & $36.4(34.7$ to 38.2$) \S$ & 34.7 (33.3 to 36.1) & 0.14 \\
\hline No with subclinical depression & $16 / 147$ & $13 / 151$ & \multirow{2}{*}{0.51} & $16 / 126$ & $5 / 136$ & \multirow{2}{*}{0.01} \\
\hline$\%(95 \% \mathrm{Cl})$ & 11 (7 to 17$)$ & $9(5$ to 14$)$ & & $13(8$ to 20$) \rrbracket$ & 4 (1 to 9$)$ & \\
\hline
\end{tabular}

Analyses in intention to treat population.

*P value difference between baseline and after intervention 0.001 .

†As specified on ClinicalTrials.gov (NCT00315029).

$\pm P$ value difference between baseline and after intervention $<0.001$

$\S \mathrm{P}$ value difference between baseline and after intervention 0.094

IP value difference between baseline and after intervention 0.439 .

$(\mathrm{P}=0.01)$. The groups did not differ significantly for anxiety levels. At uptake of in vitro fertilisation the frequency of subclinical depression did not differ between the intervention and control group: 11\% (16/147) v 9\% (113/151). After patients received the empowerment strategy, however, this frequency was higher in the intervention group $(13 \%(16 / 126)$ v $4 \% \quad(5 / 136)$; $\mathrm{P}=0.01)$; this difference diminished after embryo transfer, however (14\% (17/123) v 14\% (17/120); $\mathrm{P}=0.94)$. Within the intervention group the proportion of fully empowered couples increased significantly by $14 \%$ from baseline to after the multifaceted intervention $(\mathrm{P}=0.001)$ as did the level of experienced knowledge $(\mathrm{P}<0.001)$. Anxiety levels or the occurrence of subclinical depression did not differ significantly.

\section{Costs}

Costs of the elements of the empowerment strategy were added to the savings owing to a lower rate of twin pregnancies. Table 4 shows the mean total costs per couple, calculated in the intention to treat population ( $n=152$ ). Costs of the counselling session with the nurse were based on an average duration of 29 minutes and less than two minutes for the telephone call. Six of the 152 couples $(4 \%)$ in the intervention group used single embryo transfer in the first and second cycles but failed to become pregnant after three cycles in total. They therefore qualified for reimbursement with a fourth cycle. After computing all costs of this trial, the mean total savings in the intervention group were calculated to be $€ 169.75$ per couple included from the waiting list for in vitro fertilisation.

\section{DISCUSSION}

Patients seem willing and able to make complex decisions if they are empowered. Although this trial did not demonstrate the anticipated effect of the power calculation, the multifaceted empowerment strategy encouraged use of single embryo transfer and increased patients' knowledge. The strategy consisted of a decision aid, support of an in vitro fertilisation nurse, and an offer of reimbursement. The strategy also significantly increased the empowerment level of the couples in decision making about the number of embryos transferred and increased actual and experienced knowledge about important aspects of the decision. Levels of anxiety did not differ between couples receiving the multifaceted intervention and those receiving standard care for in vitro fertilisation. After exposure to the empowerment strategy more subclinical depression was observed in the intervention group. This could imply that participants in the intervention group needed extra psychological support after receiving the empowerment strategy. However, this difference diminished after embryo transfer, with an equal percentage of subclinical depression in the intervention and control groups. This effect on levels of depression is probably caused by the outcome (failure or success) of the treatment itself. Within this trial, the strategy reduced costs, with an average of $€ 169.75$ per couple. If these savings were extrapolated to the Dutch national level, with 7500 new couples per year, this reduction would add up to $€ 1273125$ annually. With national implementation, additional costs would be expected-for example, costs related to keeping the information up to date in the decision aid. However, with broad implementation the printing and training costs per couple would decrease noticeably and are likely to at least compensate for these additional costs.

\section{Comparison with other studies}

The results of this study are interesting in several ways. Firstly, they show that empowerment for couples choosing in vitro fertilisation can lead to noticeable effects on the choice of number of embryos transferred. Interestingly, this effect was stronger among couples 
Table $4 \mid$ Costs of multifaceted patient empowerment strategy per couple in in vitro fertilisation practice

\begin{tabular}{|c|c|}
\hline Elements of costs & $\begin{array}{l}\text { Costs per } \\
\text { couple }^{\star}(€)\end{array}$ \\
\hline \multicolumn{2}{|l|}{ Elements of empowerment strategy } \\
\hline \multicolumn{2}{|l|}{ Decision aid: } \\
\hline Print costs & 8.70 \\
\hline Postage costs & 0.45 \\
\hline \multicolumn{2}{|l|}{ IVF nurse†: } \\
\hline Training (16 hours in total) & 3.05 \\
\hline Counselling session & 100.65 \\
\hline Telephone call & 5.80 \\
\hline \multicolumn{2}{|l|}{ Reimbursement offer $\neq:$} \\
\hline Reimbursed fourth cycles & 81.75 \\
\hline \multicolumn{2}{|l|}{ Obstetrical cost reduction§ } \\
\hline Six fewer twin pregnancies & -581.35 \\
\hline \multicolumn{2}{|l|}{ Medical related costs } \\
\hline $\begin{array}{l}\text { Extra cycles to compensate for loss in chance } \\
\text { of pregnancy after single embryo transfer use }\end{array}$ & 211.20 \\
\hline Total savings & 169.75 \\
\hline \multicolumn{2}{|c|}{$\begin{array}{l}€ 1.00 \text { (£0.85; } \$ 1.23 \text { ). } \\
{ }^{*} \text { Total costs in intention to treat population (costs divided by } 152 \\
\text { intervention group couples). } \\
\text { †Based on Oostenbrink } 2004 \text { et al. } \\
\text { †Based on six couples that qualified for reimbursement (total costs } € 12 \\
426 \text { ). } \\
\S B \text { ased on fewer singleton and twin pregnancies after first and second } \\
\text { cycle in intervention group. }\end{array}$} \\
\hline
\end{tabular}

with previous experience of in vitro fertilisation than couples who underwent their first ever in cycle. A clear difference in outcome with an implementation strategy solely for patients is rare. ${ }^{2930}$ This may be because the elements of our strategy were specifically based on barriers reported by couples and professionals in previous studies. ${ }^{151619}$ The positive results of this study are even more remarkable when it is considered that professionals are still debating the necessity of preventing twin pregnancies with single embryo transfer and whether implementation of single embryo transfer should be encouraged by way of legislation or reimbursement. ${ }^{153132}$ It could be claimed that empowered couples might be more suitable to encourage the use of single embryo transfer than professionals. Secondly, with the empowerment strategy, $91 \%$ of the couples wanted to decide for themselves the number of embryos transferred (with their doctor as adviser only). Once people have received proper support they are apparently eager and capable of making such complex decisions. Thirdly, we anticipated reimbursement to have a prominent role within the strategy, but it did not. Many couples did not qualify for reimbursement because they chose double embryo transfer in the first or second cycle. Only $4 \%$ of the couples (six of 152 couples in the intervention group) qualified for reimbursement and to date only two couples have received a fourth cycle. Finally, the empowerment strategy was not designed to prevent twin pregnancies but to support the decision making process. Although this study shows a higher proportion of couples deciding on single embryo transfer, at least half of them still wanted to transfer two embryos after the first cycle. However, we have noticed an increase in couples' capability to make an informed decision. Perhaps if couples are empowered to make this decision and to comprehend the pros and cons of single embryo transfer, the strategy is already a success and one could argue about the desirability of further encouragement of single embryo transfer.

The setting in which the empowerment strategy is used is obviously important. Globally, in vitro fertilisation is carried out in different contexts, which can greatly influence the effects of our strategy. Some European countries implemented legislation prohibiting the transfer of more than one embryo, or reimbursement of single embryo transfer cycles only. ${ }^{33-35}$ In other countries higher multiple pregnancy rates exist, as a result of average higher numbers of embryos being transferred. ${ }^{14}$ The effects of this strategy can be different in these diverse settings. Still, most countries do not have compulsory legislation for single embryo transfer and previous research has shown that even with such legislation or reimbursement, total acceptance of single embryo transfer was not achievable. ${ }^{36}$ It is possible that the twinning rate of our control group is well below the European average. This is probably because in the Netherlands only a maximum of two embryos is transferred and prevention of twin pregnancies is discussed with all couples undergoing in vitro fertilisation. This resulted in a twin rate of only $6 \%$. In other settings, with higher background rates for twins, the effects of our empowerment strategy might be even more substantial. A further difference could be the magnitude of patient autonomy within the process of shared decision making. Discrepancies between countries and even clinics in how much say couples have are large. The results of our strategy might be less pronounced in settings with less patient autonomy than our participating centres. Different cultural and ethnic backgrounds of couples undergoing in vitro fertilisation (for example, desired family size) could also influence the effects of the empowerment strategy. It would therefore be interesting to observe the effects of our empowerment strategy in different populations. A final important difference is that Dutch health insurance reimburses three in vitro fertilisation cycles. The results of the strategy could be different in settings with fewer or no reimbursed cycles, especially as the absence of reimbursement is an incentive to transfer more embryos. ${ }^{17}$ But even then we would expect educated couples, who understand the risks of twin pregnancies, to be more inclined to choose single embryo transfer.

\section{Strengths and weaknesses of the study}

Although our empowerment strategy was tailored for the barriers identified by our previous research ${ }^{15} 1619$ and the decision aid was developed according to the evidence based criteria of the International Patient Decision Aids Standards,${ }^{21}$ this study also has some potential weaknesses. Firstly, from our initial power calculation we assumed that we would obtain a difference in use of single embryo transfer of $25 \%$. The $11 \%$ (95\% confidence interval $0 \%$ to $22 \%$ ) difference 


\section{WHAT IS ALREADY KNOWN ON THIS TOPIC}

Single embryo transfer prevents multiple pregnancies, with its associated complications

Although initiatives aimed to encourage single embryo transfer, in 2004 it was used in only $19 \%$ of in vitro fertilisation cycles in Europe

\section{WHAT THIS STUDY ADDS}

A multifaceted empowerment strategy effectively encouraged the use of single embryo transfer in clinical in vitro fertilisation practice

Couples receiving the strategy had significantly higher empowerment and knowledge levels but no differences in anxiety or depression compared with those receiving standard care

The strategy saved a mean total of $€ 169.75$ per couple

between intervention and control groups in this trial remained below this pre-specified goal. However, because of extensive evidence on the reduction of the twin pregnancy rate to $0-1 \%$ with use of single embryo transfer $^{7-9}$ compared with about $23 \%$ with double or multiple embryo transfer, ${ }^{14}$ the authors believe this $11 \%$ difference to be relevant for clinical practice. Secondly, the national basis of our strategy might limit generalisability as Dutch professionals and couples may perceive barriers that are different from those perceived elsewhere. None the less, most of these barriers are not specifically related to the Dutch setting, so that the results of this study are probably valid for other countries. Another potential weakness of our trial was the time of follow-up. At present, not all couples have finished all their cycles and do not know how treatment will turn out. Finally, it is difficult to assess separately the effects of the different elements of the multifaceted empowerment strategy. Although only $4 \%$ of the couples qualified for reimbursement of a fourth cycle, reimbursement may have played a part in the decision making process.

\section{Conclusions and implications}

We infer from this study that patients are willing and able to make complex decisions if they are empowered, as long as they are provided with the correct information, in an appropriate way, and in a setting with patient autonomy. Implementation of this multifaceted empowerment strategy could also help professionals working in the specialty of in vitro fertilisation as the strategy contributes to a more efficient decision making process and a reduction in costs. More research is welcomed to determine the effectiveness of the empowerment strategy in other settings and to evaluate which elements of the strategy contribute most to its effectiveness. A potential weakness of this trial could be that the $11 \%$ difference in use of single embryo transfer $(95 \%$ confidence interval $0 \%$ to $22 \%$; $\mathrm{P}=0.05$ ) remained below the anticipated 25\% difference of the power calculation.

This study illustrates that a multifaceted empowerment strategy can effectively encourage the use of single embryo transfer in clinical in vitro fertilisation practice. The strategy increases knowledge and has no substantial effect on levels of anxiety or depression. The strategy reduces costs as well, and could therefore be an important tool to reduce the twin rate after in vitro fertilisation, within a setting with patient autonomy.

We thank the participating clinics who helped with inclusion of couples and Jose Terken and Annelies Pellegrino for the counselling sessions and distribution of the questionnaires.

Contributors: AP designed the trial, developed and managed the main database, interpreted the analysis, and drafted the paper. He is guarantor. WN designed the trial, analysed and interpreted the data, and drafted the paper. RG designed and implemented the trial and drafted the paper. GZ designed the trial, interpreted the data, and drafted the paper. EA designed the trial, interpreted the cost analysis data, and drafted the paper. PS designed the evaluation of decision making variables, interpreted the decision making outcomes, and drafted the paper. $\mathrm{RH}$ designed the study, analysed and interpreted the data, and drafted the paper. JK led the trial team, was principal investigator, and drafted the paper. All authors reviewed successive drafts of the paper. Funding: This study was funded by the Netherlands Organisation for Health Research and Development (grant No 945-16-105). All researchers are independent from this source of funding. The study sponsor had no role in the study design, collection, analysis, and interpretation of data, the writing of the article, and the decision to submit it for publication.

Competing interests: All authors have completed the unified competing interest form at www.icmje.org/coi_disclosure.pdf (available on request from the corresponding author) and declare (1) no financial support for the submitted work from anyone other than their employer; (2) no financial relationships with commercial entities that might have an interest in the submitted work; (3) no spouses, partners, or children with relationships with commercial entities that might have an interest in the submitted work; and (4) no non-financial interests that may be relevant to the submitted work.

Ethical approval: The study was approved by the regional ethics committee for medical research.

Data sharing: Dataset available from corresponding author at a.vanpeperstraten@obgyn.umcn.nl.

1 Committee on Quality of Health Care in America and Institute of Medicine. Crossing the quality chasm: a new health system for the 21st century. National Academies Press, 2001.

2 Forlani G, Zannoni C, Tarrini G, Melchionda N, Marchesini G. An empowerment-based educational program improves psychological well-being and health-related quality of life in type 1 diabetes. $/$ Endocrinol Invest 2006;29:405-12.

3 Maly RC, Stein JA, Umezawa Y, Leake B, Anglin MD. Racial/ethnic differences in breast cancer outcomes among older patients: effects of physician communication and patient empowerment. Health Psychol 2008;27:728-36.

4 Ayme S, Kole A, Groft S. Empowerment of patients: lessons from the rare diseases community. Lancet 2008;371:2048-51.

5 Taylor I. Some patients are happy for doctors to make decisions. BMJ 2000;320:58.

6 Tomes N. Patient empowerment and the dilemmas of late-modern medicalisation. Lancet 2007;369:698-700.

7 Helmerhorst FM, Perquin DA, Donker D, Keirse MJ. Perinatal outcome of singletons and twins after assisted conception: a systematic review of controlled studies. BMJ 2004:328:261.

8 Pandian Z, Bhattacharya S, Ozturk O, Serour G, Templeton A. Number of embryos for transfer following in-vitro fertilisation or intracytoplasmic sperm injection. Cochrane Database Syst Rev 2009;2:CD003416.

9 Pinborg A. IVF/ICSI twin pregnancies: risks and prevention. Hum Reprod Update 2005;11:575-93.

10 Lukassen HG, Braat DD, Wetzels AM, Zielhuis GA, Adang EM, Scheenjes E, et al. Two cycles with single embryo transfer versus one cycle with double embryo transfer: a randomized controlled trial. Hum Reprod 2005;20:702-8.

11 Thurin A, Hausken J, Hillensjo T, Jablonowska B, Pinborg A, Strandell A, et al. Elective single-embryo transfer versus doubleembryo transfer in in vitro fertilization. $N$ Engl / Med 2004;351:2392-402.

12 Van Montfoort AP, Fiddelers AA, Janssen JM, Derhaag JG, Dirksen CD, Dunselman GA, et al. In unselected patients, elective single embryo transfer prevents all multiples, but results in significantly lower pregnancy rates compared with double embryo transfer: a randomized controlled trial. Hum Reprod 2006;21:338-43.

13 Prevention of twin pregnancies after IVF/ICSI by single embryo transfer. ESHRE campus course report. Hum Reprod 2001;16:790-800. 
14 Andersen AN, Goossens V, Ferraretti AP, Bhattacharya S, Felberbaum R, de Mouzon J, et al. Assisted reproductive technology in Europe, 2004: results generated from European registers by ESHRE. Hum Reprod 2008;23:756-71.

15 Van Peperstraten AM, Hermens RP, Nelen WL, Stalmeier PF, Scheffer GJ, Grol RP, et al. Perceived barriers to elective single embryo transfer among IVF professionals: a national survey. Hum Reprod 2008;23:2718-23.

16 Van Peperstraten AM, Nelen WL, Hermens RP, Jansen L, Scheenjes E, Braat DD, et al. Why don't we perform elective single embryo transfer? A qualitative study among IVF patients and professionals. Hum Reprod 2008;23:2036-42.

17 Jain T, Harlow BL, Hornstein MD. Insurance coverage and outcomes of in vitro fertilization. N Engl J Med 2002;347:661-6.

18 Kremer JA, Bots RS, Cohlen B, Crooij M, Van Dop PA, Jansen CA, et al. [Ten years of results of in-vitro fertilisation in the Netherlands 19962005.] Ned Tijdschr Geneeskd 2008;152:146-52.

19 Van Peperstraten AM, Kreuwel IA, Hermens RP, Nelen WL, Van Dop PA, Grol RP, et al. Determinants of the choice for single or double embryo transfer in twin prone couples. Acta Obstet Gynecol Scand 2008;87:226-31.

20 Van Peperstraten AM, Hermens RP, Nelen WL, Stalmeier PF, Wetzels AM, Maas PH, et al. Deciding how many embryos to transfe after in vitro fertilisation: development and pilot test of a decision aid. Patient Educ Couns 2010;78:124-9.

21 Elwyn G, O'Connor A, Stacey D, Volk R, Edwards A, Coulter A, et al. Developing a quality criteria framework for patient decision aids: online international Delphi consensus process. BMJ 2006;333:417.

22 Luszczynska A, Scholz U, Schwarzer R. The general self-efficacy scale: multicultural validation studies. J Psychol 2005;139:439-57.

23 Stalmeier PF, Roosmalen MS, Verhoef LC, Hoekstra-Weebers JE, Oosterwijk JC, Moog U, et al. The decision evaluation scales. Patient Educ Couns 2005;57:286-93.

24 Van der Bij AK, de Weerd S, Cikot RJ, Steegers EA, Braspenning JC Validation of the Dutch short form of the state scale of the Spielberger State-Trait Anxiety Inventory: considerations for usage in screening outcomes. Community Genet 2003;6:84-7.

25 Steer RA, Cavalieri TA, Leonard DM, Beck AT. Use of the Beck Depression Inventory for Primary Care to screen for major depression disorders. Gen Hosp Psychiatry 1999;21:106-11.
26 Oostenbrink JB, Bouwmans CAM, Koopmanschap MA, Rutten FFH. Handleiding voor kostenonderzoek. 2008. www.cvz.nl/binaries/ live/CVZ_Internet/hst_content/nl/documenten/rubriek +zorgpakket/cfh/handleiding+kostenonderzoek.pdf.

27 Lukassen HG, Schonbeck Y, Adang EM, Braat DD, Zielhuis GA, Kremer JA. Cost analysis of singleton versus twin pregnancies after in vitro fertilization. Fertil Steril 2004;81:1240-6.

28 Beck AT, Guth D, Steer RA, Ball R. Screening for major depression disorders in medical inpatients with the Beck Depression Inventory for Primary Care. Behav Res Ther 1997;35:785-91.

29 Harrington J, Noble LM, Newman SP. Improving patients' communication with doctors: a systematic review of intervention studies. Patient Educ Couns 2004;52:7-16

30 O'Connor AM, Stacey D, Entwistle V, Llewellyn-Thomas H, Rovner D, Holmes-Rovner M, et al. Decision aids for people facing health treatment or screening decisions. Cochrane Database Syst Rev 2003;3:CD001431.

31 Gleicher N, Barad D. The relative myth of elective single embryo transfer. Hum Reprod 2006;21:1337-44.

32 Van Wely M, Twisk M, Mol BW, van der Veen F. Is twin pregnancy necessarily an adverse outcome of assisted reproductive technologies? Hum Reprod 2006;21:2736-8.

33 Gordts S, Campo R, Puttemans P, Brosens I, Valkenburg M, Norre J, et al. Belgian legislation and the effect of elective single embryo transfer on IVF outcome. Reprod Biomed Online 2005;10:436-41.

34 De Neubourg D, Gerris J, Van Royen E, Mangelschots K, Vercruyssen M. Impact of a restriction in the number of embryos transferred on the multiple pregnancy rate. Eur J Obstet Gynecol Reprod Biol 2006;124:212-5.

35 Karlstrom PO, Bergh C. Reducing the number of embryos transferred in Sweden-impact on delivery and multiple birth rates. Hum Reprod 2007;22:2202-7.

36 Saldeen P, Sundstrom P. Would legislation imposing single embryo transfer be a feasible way to reduce the rate of multiple pregnancies after IVF treatment? Hum Reprod 2005;20:4-8.

Accepted: 19 April 2010 